\title{
Test designs for evaluating the effectiveness of mail packs
}

Received: 30th November, 2001

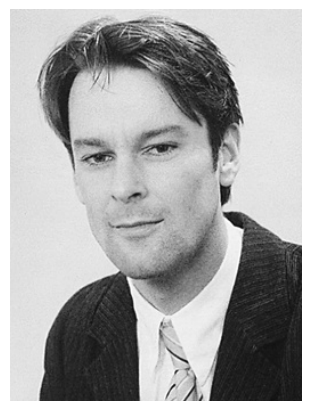

\section{Leonard Paas}

previously worked as a senior consultant at the Database Marketing Centre of Postbank. He worked on issues such as data mining, predictive modelling, controlling data quality, customer segmentation and credit scoring. He is currently working on similar issues at a consulting firm. He is also a PhD candidate at Tilburg University.

Abstract There has been a tremendous increase in the attention paid to interactive direct channels like online call centres and the Internet. Despite declining interest in the literature, direct mail can still be considered an important channel for offering products to consumers. Large investments are made in direct mail and many companies still send out millions of mail packs a year. Many marketers, however, are unaware of the best ways to determine which mail packs get the best response. The latter is the topic of the current paper.

\section{INTRODUCTION}

In the 1990s there was a massive increase in the use of direct channels, such as online call centres, direct mail and the Internet. This increase occurred at the expense of personal channels, such as intermediaries, clerks and independent agents, particularly in the financial services sector. The first direct channel that was exploited on a grand scale was direct mail. Early direct mail campaigns can be characterised by their massive size - millions of prospects receiving the same mail pack offering the same product at the same time, via the same message. This started to change when decision makers in companies found that some prospect segments had extremely low response propensities. For example, it is now generally known that shares should not be offered to individuals with few savings and low incomes. Because of their situation they will not acquire the product, regardless of the manner in which the offer is forwarded. Moreover, it was found that certain products were not suitable for marketing via direct mail. For example, in the Netherlands a complex product such as a mortgage is still acquired via personal channels by most consumers.

Other observations are that the timing of the offer and the features of the mail pack influence a prospect's propensity to respond. For example, sending a reminder increases the response rate by 50 per cent. In addition, response rates can be enhanced by including gifts, by offering different ways to respond (by phone, in writing etc.) or even by changing the colour of the mail pack. These insights led to the following factors which influence the success of mail campaigns:

- propensity of selected prospects to respond

- product characteristics

- timing

- mail pack characteristics.

The last factor is usually considered the least important. It is, however, proposed 
that this does not mean that the characteristics of the mail pack are of no consequence. To illustrate this the limitations of the three other factors are discussed.

The first factor has to do with selecting prospects with the greatest expected response rate. This implies that packs are not sent to all prospects, just to those prospects with a certain minimum propensity to respond. This usually leads to a higher response rate, but a lower absolute number of respondents. That is, the highest absolute number of respondents is obtained by mailing a pack to every prospect in the target group, excluding segments of prospects leads to a lower absolute number of respondents. Thus, selection criteria cannot lead to more respondents in an absolute sense. Selection criteria can only lead to higher response rates. With higher response rates the number of mail packs sent out can be reduced. In this way the efficiency of the mailing is increased because costs are reduced.

Changing the product could lead to a higher absolute response, ie a product with more desirable properties for prospects will lead to a greater absolute number of respondents if packs are mailed to all prospects. Changing products, however, is not always possible, perhaps because of legislation or the costs involved. Thus, timing and the characteristics of the mail pack are generally the only factors that can be used to increase the absolute number of respondents.

Testing the effects of timing is relatively simple. The same offer can be made at different points in time and then the point in time which led to the highest response rate can be analysed. The timing effects can also be investigated for different segments of prospects and then the results can be used to determine when members of each segment should receive which mail pack.

Measuring the effect of mail pack characteristics can, however, be more complex. The effect of mail packs can be at three levels:

— the general level: ie is a higher response rate obtained from prospects with mail pack A than with $B$

- the effect of the mail pack among different groups of prospects: ie does mail pack A lead to a higher response rate among clients under 35 years of age than mail pack $B$ does

- the effectiveness of different mail pack characteristics among different groups: ie does the gift included with mail pack A lead to a higher response rate among prospects under 35 years of age than mail pack $B$ ?

Mail pack effects have received relatively little attention in the literature. In particular, issues regarding the test design necessary to evaluate their effectiveness have been more or less completely ignored, to the best of the author's knowledge. The current study discusses the necessary test design for testing the effectiveness of mail packs at each of the three levels described above.

\section{GENERAL EFFECTIVENESS OF MAIL PACKS}

As suggested above, the effectiveness of mail packs depends on the packs' characteristics. Various characteristics are relevant in this regard, eg the colour of the envelope, use of a gift (such as a calculator, beach towel or Parker pen), the manner in which the subject may respond (ie by acquiring the product directly, direct offer, asking for a more specific written offer, indirect offer). Based on the characteristics that are used 
Table 1: General effectiveness of the mail packs

\begin{tabular}{lll}
\hline $\begin{array}{l}\text { No. mail } \\
\text { pack }\end{array}$ & Characteristics of the mail pack & Response rate \% \\
\hline 1 & Direct offer in a green envelope with a gift & 10 \\
2 & Indirect offer in a white envelope without a gift & 6 \\
3 & Direct offer in a white envelope with a gift & 6 \\
4 & Direct offer in a white envelope without a gift & 8 \\
\hline
\end{tabular}

as examples, the following mail packs could be developed (note that these are just a few possible examples):

- a direct offer in a green envelope with a gift

- an indirect offer in a white envelope without a gift

- a direct offer in a white envelope with a gift

- a direct offer in a white envelope without a gift.

Other combinations are possible. The costs would, however, be very high if all conceivable mail packs were developed and used. This explains why the development of mail packs is often considered a creative process, where the marketer's intuition about pack effectiveness is important.

This paper agrees with the importance of creativity in mail pack design. It is also proposed, however, that the effectiveness of different mail packs (in terms of generating response) should always be tested empirically. To achieve this the target group for the proposed direct mail campaign should be split into multiple random groups. Each group then receives another mail pack. The mail pack that led to the highest response rate can be considered the most effective and should be used in future campaigns that are intended for the same target group. This conclusion can be drawn because the groups that received the different packs were randomly selected and, therefore, only differed with regard to the mail pack they received. In these circumstances differences in response can only be due to the mail pack received.

In practice, mistakes are often made. Different mail packs are sent to different groups, so that differences in response rates can be caused by either differences in the characteristics of the group or by differences in the mail packs that were used. Using incorrect definitions for random selections is another common mistake. For example, 10,000 clients might be selected for a test of two mail packs, the clients with the 5,000 lowest bank account numbers receiving mail pack $A$, the rest receiving mail pack $B$. Clients receiving mail pack A may, however, have become clients earlier than those receiving mail pack $\mathrm{B}$. In this example differences in response rates could be caused by the fact that older clients are more loyal and interested in offers made by the company. Such problems can be avoided by using the standard randomisers available in statistical software such as SPSS or SAS.

If a proper random selection has been made it is relatively simple to determine which mail pack leads to the highest response rate in the target group. In the above example of four mail packs the results presented in Table 1 could be obtained. These fictitious results imply that mail pack 1 is the most effective in terms of creating response in the defined target group. Table 1 suggests that the whole target group should receive mail pack 1 in future campaigns, under the 
assumption that the price of all mail packs is the same. If the prices of mail packs differ which mail pack leads to the highest profit should be calculated, by deducting the cost of the mail packs from the value of the responses. The mail pack leading to the highest profit is then considered the most effective. In practice this is not always the mail pack leading to the highest response rate, sometimes a cheap mail pack leads to a marginally lower response rate than a substantially more expensive mail pack.

\section{EFFECTIVENESS OF THE MAIL PACKS FOR DIFFERENT GROUPS OF PROSPECTS}

An advantage of finding the best mail pack for the whole target group is that developing and using one mail pack leads to relatively low logistic costs. This approach has a disadvantage however. In a study by Bult, Van der Scheer and Wansbeek $^{1}$ it was found that the effectiveness of mail packs is not the same for all types of prospects. For example, a mail pack that leads to the highest response among prospects under 30 years of age, may be relatively ineffective for prospects over 60 years of age. Thus, it may be worthwhile to use multiple mail packs, despite the higher logistic costs. In this section of the paper a relatively simple approach to prospect selection in such a situation is discussed.

In the conventional prospect selection approach decision makers utilise a single predictive model for estimating the response rate for each prospect. The predicted response rate can then be used to decide whether a prospect should receive the direct mail offer. If the cost of mailing the pack to the prospect is lower than the expected yield, then this individual should be sent a pack. ${ }^{2}$ The predicted probability of responding in this case is based on the assumption that all prospects receive the mail pack that led to the highest overall response rates in earlier experiments.

Instead of building one predictive model multiple models could be developed to predict the probability of responding to each mail pack. In the hypothetical example used in the previous section of the paper this would imply building four predictive models. For example, consider that six months after the models are built a marketer decides to approach the target group again, offering the same product that was marketed previously. Here the random mailings represented in Table 1 for building the four required predictive models could be used. After building the models each prospect on each of the four available models can be scored. Using the predicted probabilities for responding on each mail pack, the expected profit resulting from each pack can be calculated by subtracting the cost of sending each pack from the expected yield. The latter is based on the expected probability of responding and the value of a respondent. If the expected yield for a particular prospect is negative on each mail pack, then this person should not be sent a pack. If, however, the expected yield is positive on one or more of the available mail packs, then the prospect should receive the mail pack leading to the highest positive yield.

Assuming that in the fictitious example of the four mail packs the price of developing each pack is the same, mail pack 4 would be sent to prospect 1 , see Figure 1. Note that, at the general level, mail pack 1 has the highest expected response rate (see Table 1). Differences like this have often been found in practice. Ensuring that the right mail pack is sent to the right prospect under such circumstances has led to increases in response of up to 40 per cent, compared to just sending the best average mail 


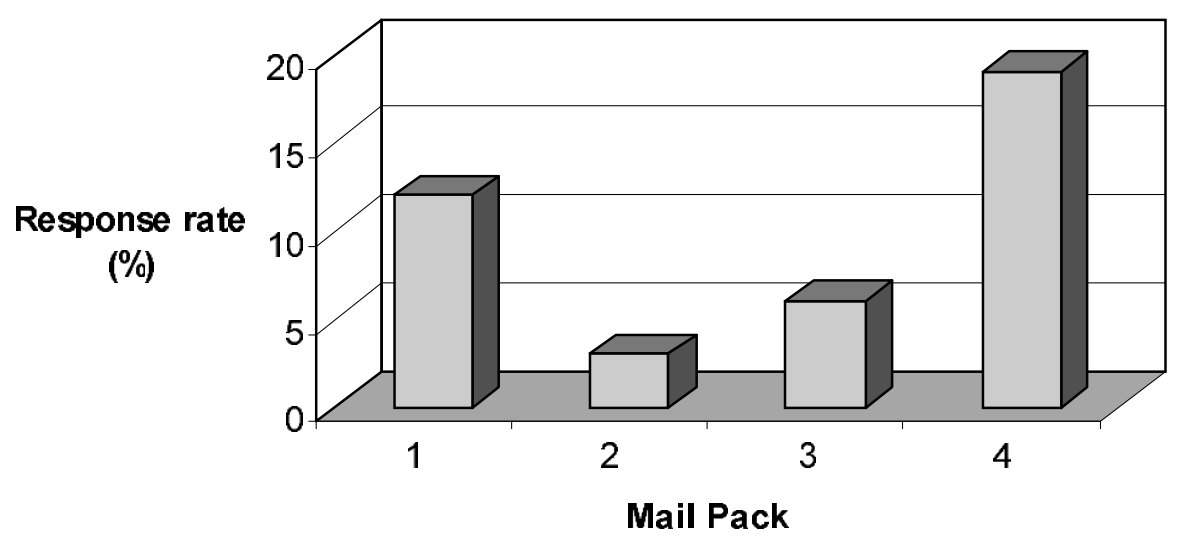

Figure 1: Response rates per mail pack for prospect 1

pack to each prospect. Such increases in response usually more than compensate for the higher investment that has to be made.

\section{EFFECTIVENESS OF MAIL PACK CHARACTERISTICS FOR DIFFERENT PROSPECTS}

Some of the first propositions put forward in this paper concern the important role of creativity in the design of mail packs. In the previous sections it was shown that the effectiveness of this creative process can be tested. Test designs that could enhance the creative process itself are described next. That is, techniques enabling marketers to determine the effectiveness of individual characteristics in the mail pack are put forward. Note that the study by Bult, Van der Scheer and Wansbeek ${ }^{3}$ also addresses this topic. This study did not, however, discuss the test design supporting analyses into the interaction between characteristics of mail packs and prospects. The latter is the main topic of the current section of this paper.

It was pointed out previously that it is too expensive to produce and use every possible mail pack for direct mail campaigns. Creativity is thus important for finding effective combinations of mail pack characteristics. A well-chosen test design can also support this aspect of the creative process. At a general level it is fairly simple to determine what is likely to be the best combination of mail pack characteristics. The relevant test design can be described using the previous example, where variations were made in the colour of the envelope, use of a gift (yes or no) and the way the subject can respond (directly or indirectly). If it is assumed that the envelope can have three colours (blue, green, white), then there are 12 possible types of mail packs, see Figure 2. Use of an appropriate test design could, however, reduce the number of mail packs required for determining which combination of characteristics leads to the highest average response rate in the target group. This can be described using Figure 2.

Each cell in the two $3 \times 2$ tables incorporated in Figure 2 represents a possible mail pack. As mentioned before, it is possible to develop 12 different types of mail packs. The effects of individual mail pack characteristics can, however, be estimated by developing only the five mail packs represented by the table cells containing a starred number. First of all, the effect of a gift 


\begin{tabular}{|c|c|c|}
\hline \multirow{3}{*}{ Colour } & \multicolumn{2}{|c|}{ Direct response pack } \\
\hline & \multicolumn{2}{|c|}{ Gift } \\
\hline & Yes & No \\
\hline Blue & $\star 1$ & $\star 2$ \\
\hline White & $\star 3$ & \\
\hline Green & $\star 4$ & \\
\hline
\end{tabular}

Figure 2: Posssible test design

can be estimated by comparing the response to mail pack $\star 1$ (direct response pack, with gift, in a blue envelope) with the response rate realised through mail pack $\star 2$ (direct response pack, without gift, in a blue envelope). Mail packs $\star 1$ and $\star 2$ only differ in whether or not a gift is included. This implies that differences in response rates can be completely attributed to this specific mail pack characteristic, assuming that both mail packs were sent to a random selection of prospects. Similarly, the effect of colour can be evaluated by comparing the response rates realised through mail packs $\star 1, \star 3$ and $\star 4$. These mail packs only differ with regard to colour, so here any differences in response rate can be explained by this particular characteristic. Lastly, the effect of the way the prospect can respond is established by comparing the response to mail pack $\star 1$ with the response to mail pack $\star 5$.

There can also be interaction between mail pack characteristics and prospect characteristics. ${ }^{4}$ As mentioned above, different prospects or segments of prospects have different ideal mail packs. The suitability of mail pack characteristics may also vary for different prospects or segments. The test design in Figure 2 can also be used to tailor make a mail pack for each type of prospect. Using the proposed test design a model for each developed mail pack $(\star 1, \star 2$, $\star 3, \star 4$ and $\star 5$ ) would be developed. For prospects with a higher expected response rate on mail pack $\star 1$ than on mail pack $\star 2$ a pack with a gift would have to be developed. To determine the ideal colour the expected response rates on mail packs $\star 1, \star 3$ and $\star 4$ would be compared. Whether the prospect receives a direct or an indirect offer is determined by comparing the response rates to packs $\star 1$ and $\star 5$. Each comparison leads to an ideal characteristic with regard to a specific attribute and the combination of ideal characteristics leads to the best mail pack for an individual prospect.

Some remarks about costs have to be made before concluding this section of the paper. Combining the best possible characteristics for each individual prospect can lead to a large number of mail packs, particularly in practice where mail packs can have more variations than in the hypothetical example in Figure 2. This can be easily dealt with - mail packs should only be developed if the pack leads to a maximum possible response rate among a certain minimum number of prospects (eg 10,000).

\section{DISCUSSION}

The ideas presented above have been put into practice by financial services providers in the Netherlands. It is, however, still possible to see inefficient testing of mail pack effectiveness. It even 
happens that test designs are set up to evaluate the effectiveness of mail packs when different target groups have been approached with different packs. It is suggested that such practices be avoided, because a quick sale may be made in the short term, but nothing is learned for the future. This means there is a great risk of using suboptimal mail packs over long periods.

To conclude the paper some suggestions for further reading are made. The study discussed some important aspects of test design that are particularly relevant for evaluating the effectiveness of direct mail packs. Readers requiring a more extensive and general insight into test design are referred to a book by Rosenbaum, which includes suggestions for setting up test designs and handling results from experiments with a suboptimal test design. ${ }^{5}$ Furthermore, more detailed analyses can be conducted into the interaction between the characteristics of mail packs and prospects — see Bult, Van der Scheer and Wansbeek. ${ }^{6}$

\section{References}

1 Bult, J. R., Van der Scheer, H. and Wansbeek, T. (1997) 'Interaction between target and mailing characteristics, with an application to health care fund raising', International Journal of Research in Marketing, Vol. 14, pp. 301-308.

2 Paas, L. (1999) 'Revenue-driven direct mail campaigns', The Journal of Database Marketing, Vol. 6, No. 4, pp. 321-329.

3 Bult et al. (1997) op. cit.

4 Bult et al. (1997) op. cit.

5 Rosenbaum, P. R. (1995) 'Observational studies', Springer-Verlag, New York.

6 Bult et al. (1997) op. cit. 